
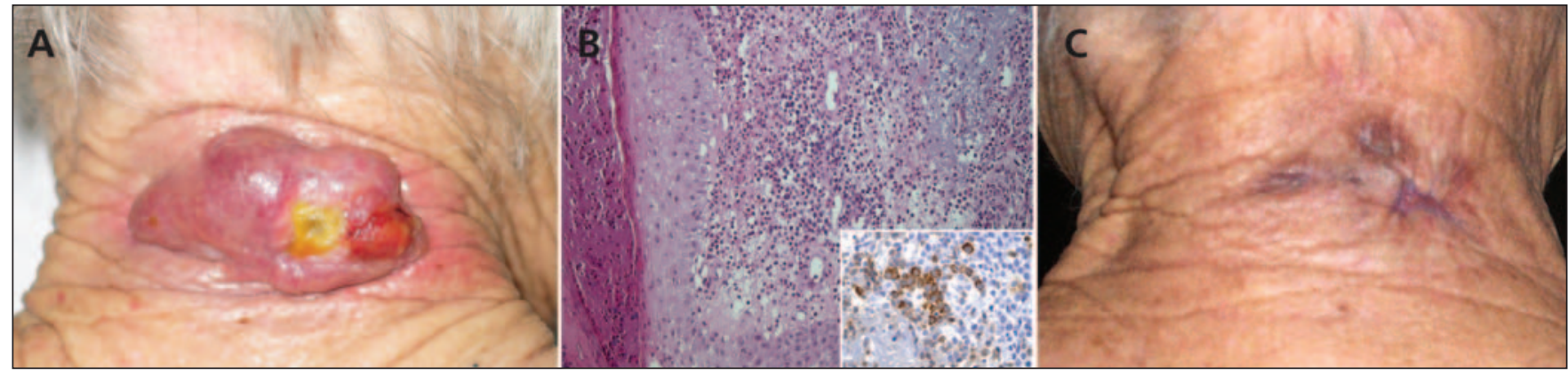

Figure 1: A: An 89-year-old woman with a painful neck mass $(5 \mathrm{~cm} \times 3 \mathrm{~cm})$. B: A biopsy of the mass showed massive infiltration of the subcutaneous connective tissue by eosinophilic cells (original magnification $\times 220$ ), with intensely positive staining for myeloperoxidase (insert: original magnification $\times 440$ ). C: The tumour regressed 4 months after treatment.

\title{
Granulocytic sarcoma of the skin
}

A n 89-year-old woman with refractory anemia presented with a painful neck mass that measured $5 \mathrm{~cm} \times 3 \mathrm{~cm}$ (Figure 1A). Her peripheral leukocyte count was $\left(118 \times 10^{9} / \mathrm{L}\right)$, with $98 \%$ immature blood cells. A biopsy of the mass showed massive infiltration of the subcutaneous connective tissue by eosinophilic cells (Figure 1B). Clusters of these cells stained intensely positive for myeloperoxidase (Figure 1B insert), which confirmed the diagnosis of granulocytic sarcoma.

Granulocytic sarcomas are extramedullary tumours associated with acute myeloid leukemia. They are also known as chloromas because they express myeloperoxidase and therefore appear green or turn green in the presence of dilute acid.

For our patient, cytoreduction was achieved with a low-dose oral etoposide, and the neck mass was controlled by electron beam radiotherapy. Four months later, the patient remained in fair condition. Figure 1C shows complete regression of the neck lesion, which was replaced by a pigmented scar.

Clinical images are chosen because they are particularly intriguing, classic or dramatic.

Submissions of clear, appropriately labelled high-resolution images must be accompanied by a figure caption and the patient's written consent for publication. A brief explanation (300 words maximum) of the educational significance of the images with minimal references is required.
Mario Pirisi MD

Marco Krengli MD

Guido Valente MD

Department of Clinical and Experimental Medicine

University of Eastern Piedmont Amedeo Avogadro

Novara, Italy 